\title{
As câmaras municipais brasileiras: perfil de carreira e percepção sobre o processo decisório local
}

\author{
Maria Teresa Miceli Kerbauy \\ Universidade Estadual Paulista - Campus de \\ Araraquara
}

\begin{abstract}
Resumo
Neste artigo, o legislativo municipal é analisado a partir de dois eixos: (1) a ênfase em suas características nacionais e regionais, com base em dados sobre a composição social e político-partidária do legislativo municipal no Brasil, no período de 1996, 2000 e 2004; e (2) os diferentes modos como os poderes legislativos locais de São Paulo e Santa Catarina percebem os poderes executivos no que se refere ao processo decisório.
\end{abstract}

Palavras-chave: vereadores, poder executivo, poder legislativo, câmara municipal, Brasil.

\begin{abstract}
This article analyses two main aspects about the Brazilian legislative at the local level: (1) the regional and national characteristics based on the social basis and the party links of local representatives in 1996, 2000 and 2004, and (2) the different views the local representatives and mayors conceive the local decision making process, especifically in the states of São Paulo and Santa Catarina.
\end{abstract}

Keywords: local representatives, executive, legislative, local chamber, Brazil. 
A Constituição de 1988 resgatou definitivamente o papel do município no cenário político brasileiro, ao torná-los entes federados com constituições próprias e ao dar-Ihes relativa autonomia político-jurídica, , acompanhando a tendência internacional de valorizar os níveis subnacionais de governo.

Os avanços descentralizadores que já vinham ocorrendo antes de 1988, através de sucessivas emendas constitucionais para ampliação dos percentuais do Fundo de Participação dos Estados e Municípios, tornaram-se mais rápidos com a descentralização dos recursos fiscais. Em conseqüência, os municípios passaram a ter um maior volume de encargos relativos às políticas sociais e às ações de desenvolvimento econômico local, dando aos governos locais uma capacidade de intervenção efetiva na construção de uma agenda de políticas públicas. Deve-se ressaltar que os municípios receberam a maior parcela dos aumentos resultantes das transferências constitucionais e foram os principais favorecidos pela descentralização de competências na área social.

O Brasil tem hoje 5.563 municípios, dos quais 1.363 foram criados a partir de 1989, graças às regras flexíveis estabelecidas pelo artigo $18, \S 4^{\circ}$, da Constituição de 1988, definidas para preservar "a continuidade e unidade histórico. cultural do ambiente urbano, obedecidos os requisitos previstos em lei complementar estadual e mediante consulta prévia às populações diretamente envolvidas". O resultado visível do aumento do número de municípios na última década é o fato de $90 \%$ deles terem menos de 50 mil habitantes, e $80 \%$ de suas despesas serem cobertas por transferências institucionais.

Apesar de a agenda política, econômica e social ter sido tomada por intensas discussões sobre o papel do município - as relações inter-governamentais, questões fiscais e tributárias, a governança democrática, propostas de novos arranjos institucionais locais visando à interação de governo e município -, pouco se discutiu sobre o papel do legislativo municipal neste novo contexto. O assunto só voltou à cena quando o Tribunal Superior Eleitoral (TSE) reduziu de 60.276 para 51.748 o número de vereadores. Estima-se que o custo dos legislativos municipais deva ser reduzido de 4,8 bilhões para 550 milhões por ano, devido à diminuição do número de salários pagos a vereadores e seus assessores. Com a nova tabela elaborada pelo TSE para escalonamento de vereadores, uma cidade que, antes, chegava a ter até 22 vereadores, teve o limite reduzido para até 9 vagas ${ }^{1}$.

O novo desenho institucional municipal articula novos atores políticos - os conselhos municipais - com os quais o executivo, o legislativo e o sistema jurídico devem interagir. O legislativo, por sua vez, fica diluído neste novo desenho.

\footnotetext{
${ }^{1} \mathrm{O}$ artigo 29 (IV b) da Constituição de 1988 é bastante flexível ao estabelecer que os municípios com até 1 milhão de habitantes devem ter no mínimo 9 e no máximo 21 vereadores.
} 
Estudos recentes de Andrade (1998) analisam as estratégias parlamentares adotadas no processo de tomada de decisões da Assembléia Legislativa do Estado de São Paulo e da Câmara Municipal de São Paulo e Ávila Filho e outros (2004) apontam para as dificuldades das câmaras municipais em produzir legislação municipal significativa, dados os constrangimentos decorrentes das constituições federal e estadual:

"Diante destas dificuldades, outros serão os mecanismos através dos quais os vereadores poderão acessar a preferência do eleitor a partir de sua atividade no legislativo /.../ Indicações, solicitações e requerimentos, cuja função o senso comum sugere ser uma "perfumaria", podem ser instrumentos de costura de redes políticas. (ÁVILA FILHO, 2004, p. 3-4)"

Com relação à bibliografia sobre poder local, poucos estudos foram dedicados à atuação do legislativo municipal, às regras que determinam o processo de interação dos poderes executivo e legislativo e de como se orientam as ações dos atores políticos do legislativo local. As análises sobre o "comportamento legislativo" restringiram-se à atuação da câmara dos deputados e das assembléias legislativas (FIGUEIREDO \& LIMONGI, 1999; SANTOS, 2001; PEREIRA \& RENNÓ, 2001). Daí a dificuldade de extrapolar para o município as análises efetuadas por Figueiredo \& Limongi (1999), a respeito do predomínio do executivo no processo de formulação de políticas, caracterizado por um padrão cooperativo entre os dois poderes.

Este artigo apresenta alguns dados sobre a composição do legislativo municipal no Brasil, no período de 1996 a 2000, e analisa suas características sociais e partidário-eleitorais em uma dimensão praticamente ignorada nas análises sobre poder local. Também analisa o perfil dos presidentes das câmaras dos estados de São Paulo e Santa Catarina, com especial atenção às questões referentes à opção partidária. Por fim, analisar os diferentes modos como os poderes legislativos locais de São Paulo e de Santa Catarina percebem os poderes executivos, no que se refere ao processo decisório, e procura mostrar como as diferenças apontadas entre os estados estão correlacionadas ao tamanho dos municípios e ao grau de urbanização.

O argumento é que apesar das inúmeras mudanças na Constituição e da enorme transformação da sociedade brasileira, continuam sendo utilizadas na análise do legislativo municipal as mesmas referências que serviram para contar a história político-institucional do país de décadas anteriores. Os dados gerais atuais sobre o legislativo apontam a necessidade de outras alternativas de análise. 


\section{0 perfil de carreira dos vereadores}

Os dados sobre os 27 estados brasileiros para as legislaturas 1996, 2000 e 2004, foram coletados junto ao Tribunal Superior Eleitoral (TSE). Os dados relativos ao ano de 1996 apresentam uma série de falhas e inconsistências, apontadas pelo próprio tribunal. Essas lacunas foram corrigidas em 2000, quando houve um aumento de $17 \%$ nas cadeiras do legislativo local e melhoradas substancialmente em 2004.

O perfil de carreira dos parlamentares municipais permite debater as suas características socioeconômicas, que servem para análises mais aprofundadas sobre o papel da vereança, sobre a organização interna e a produção legal dos poderes legislativos subnacionais, sobre o sistema eleitoral e, em especial, sobre o sistema partidário brasileiro.

Uma característica marcante das câmaras municipais brasileiras é sua composição predominantemente masculina, repetindo o que se verifica nos legislativos estadual e federal, embora o contingente de eleitores do sexo feminino seja maior do que o de eleitores do sexo masculino, para todo o período apresentado.

Tabela 1

Composição das câmaras municipais, segundo o sexo Brasil - eleições de 1996, 2000 e 2004

\begin{tabular}{|l|c|c|c|c|c|c|}
\hline & \multicolumn{2}{|c|}{1996} & \multicolumn{2}{c|}{2000} & \multicolumn{2}{c|}{$\mathbf{2 0 0 4}$} \\
\hline & $\mathbf{N}$ & $\mathbf{\%}$ & $\mathbf{N}$ & $\mathbf{\%}$ & $\mathbf{N}$ & $\mathbf{\%}$ \\
\hline Homens & 42.720 & 89,97 & 49.029 & 88,37 & 45.947 & 88,67 \\
\hline Mulheres & 4.762 & 10,03 & 6.454 & 11,63 & 5.872 & 11,33 \\
\hline Totais & $\mathbf{4 7 . 4 8 2}$ & $\mathbf{1 0 0}$ & $\mathbf{5 5 . 4 8 3}$ & $\mathbf{1 0 0}$ & $\mathbf{5 1 . 8 1 9}$ & $\mathbf{1 0 0}$ \\
\hline
\end{tabular}

Fonte: TSE - Tribunal Superior Eleitoral

Analisados por região, esses dados mostram pequenas diferenças. O Norte, Nordeste e Centro-Oeste têm um número ligeiramente superior de vereadoras. 
Tabela 2

Porcentagem de Mulheres Vereadoras, por Região Brasil - eleições de 1996, 2000 e 2004

\begin{tabular}{|l|c|c|c|}
\hline & $\mathbf{1 9 9 6}$ & $\mathbf{2 0 0 0}$ & $\mathbf{2 0 0 4}$ \\
\hline Norte & 12,86 & 14,19 & 14,60 \\
\hline Nordeste & 12,45 & 13,25 & 14,59 \\
\hline Sudeste & 7,93 & 10,38 & 10,61 \\
\hline Sul & 8,15 & 10,06 & 11,43 \\
\hline Centro-Oeste & 12,28 & 12,19 & 13,42 \\
\hline
\end{tabular}

Fonte: TSE - Tribunal Superior Eleitoral

Quanto à escolaridade, a maioria dos vereadores do sexo masculino limitase ao segundo grau completo. A maioria das mulheres vereadoras têm grau de instrução um pouco mais elevado do que os homens. $E$ a maior parte das vereadoras que obtiveram grau de instrução superior estão nas regiões Sudeste e Sul.

Tabela 3

Distribuição dos vereadores segundo o grau de instrução Brasil - eleições de 1996, 2000 e 2004

\begin{tabular}{|l|c|c|c|c|c|c|}
\hline \multirow{2}{*}{ Grau de Instrução } & \multicolumn{3}{|c|}{ Homens \% } & \multicolumn{3}{c|}{ Mulheres \% } \\
\cline { 2 - 7 } & $\mathbf{1 9 9 6}$ & $\mathbf{2 0 0 0}$ & $\mathbf{2 0 0 4}$ & $\mathbf{1 9 9 6}$ & $\mathbf{2 0 0 0}$ & $\mathbf{2 0 0 4}$ \\
\hline Não informado & 38,30 & 1,78 & 10,62 & 33,60 & 1,95 & 8,00 \\
\hline Lê e escreve & 5,19 & 5,32 & 19,98 & 2,50 & 4,04 & 9,60 \\
\hline $1^{\circ}$ grau incompleto & 19,70 & 26,05 & 3,65 & 11,72 & 11,96 & 1,74 \\
\hline $1^{\circ}$ grau completo & 9,78 & 15,17 & 21,07 & 8,00 & 8,91 & 28,73 \\
\hline $2^{\circ}$ grau incompleto & 4,84 & 7,52 & 4,78 & 4,77 & 10,32 & 4,05 \\
\hline $2^{\circ}$ grau completo & 11,92 & 24,44 & 10,57 & 21,34 & 30,37 & 25,34 \\
\hline Superior incompleto & 2,34 & 4,98 & 3,87 & 3,13 & 12,16 & 6,69 \\
\hline Superior completo & 7,93 & 14,73 & 25,45 & 14,95 & 20,28 & 15,84 \\
\hline Total & $\mathbf{1 0 0 , 0}$ & $\mathbf{1 0 0 , 0}$ & $\mathbf{1 0 0}$ & $\mathbf{1 0 0 , 0}$ & $\mathbf{1 0 0 , 0}$ & $\mathbf{1 0 0}$ \\
\hline
\end{tabular}

Fonte TSE - Tribunal Superior Eleitoral

Há diferenças significativas na comparação da escolaridade dos vereadores, por regiões de origem. A maior parte dos vereadores das regiões Norte, Nordeste e Centro-Oeste tem, no máximo, o segundo grau completo ou o primeiro grau incompleto. Nas regiões Sul e Sudeste, o número de vereadores que completaram o primeiro grau é ligeiramente superior ao dos que têm o segundo grau completo. As duas regiões concentram o maior número de vereadores com superior incompleto e completo. Ressalte-se, ainda, que a região Nordeste concentra a maior taxa de vereadores com capacidade instrucional limitada apenas à leitura e escrita; essa taxa se inverte quando se considera a maior capacitação instrucional dos vereadores que representam a região Sul. 
Os níveis de escolaridade alcançados estão aparentemente relacionados à origem social ${ }^{2}$ dos vereadores, como veremos a seguir, e ao conjunto de diferenças regionais, conforme revelam os dados da Tabela 4.

\section{Tabela 4}

Distribuição dos vereadores segundo o grau de instrução, por região e por sexo Brasil - eleições de 1996 e 2000 (em \%)

\begin{tabular}{|c|c|c|c|c|c|c|c|c|c|c|c|c|c|c|c|c|c|c|c|c|c|}
\hline \multirow{3}{*}{\begin{tabular}{|c|} 
Grau \\
de \\
Instru- \\
ção \\
\end{tabular}} & \multirow{3}{*}{\begin{tabular}{|c|} 
Região \\
Ano \\
Sexo
\end{tabular}} & \multicolumn{4}{|c|}{ Norte } & \multicolumn{4}{|c|}{ Nordeste } & \multicolumn{4}{|c|}{ Sudeste } & \multicolumn{4}{|c|}{ Sul } & \multicolumn{4}{|c|}{ Centro-Oeste } \\
\hline & & \multicolumn{2}{|c|}{1996} & \multicolumn{2}{|c|}{2000} & \multicolumn{2}{|c|}{1996} & \multicolumn{2}{|c|}{2000} & \multicolumn{2}{|c|}{1996} & \multicolumn{2}{|c|}{2000} & \multicolumn{2}{|c|}{1996} & \multicolumn{2}{|c|}{2000} & \multicolumn{2}{|c|}{1996} & \multicolumn{2}{|c|}{2000} \\
\hline & & H & M & H & M & $\mathbf{H}$ & M & H & M & H & M & $\mathbf{H}$ & M & H & M & H & M & H & M & H & $\mathbf{M}$ \\
\hline \multicolumn{2}{|c|}{ Lê e escreve } & 6,78 & 2,89 & 7,50 & 3,19 & 10,34 & 4,32 & 10,47 & 3,90 & 3,05 & 1,38 & 2,80 & 1,24 & 1,25 & 0,22 & 1,43 & 9,91 & 4,07 & 1,90 & 3,10 & 0,83 \\
\hline \multicolumn{2}{|c|}{$\begin{array}{l}1^{\circ} \text { grau } \\
\text { incomp. }\end{array}$} & 25,63 & 15,99 & 27,49 & 15,80 & 17,97 & 11,65 & 25,68 & 13,38 & 17,06 & 9,76 & 25,49 & 10,37 & 22,42 & 10,82 & 26,51 & 9,91 & 25,93 & 15,71 & 28,50 & 10,33 \\
\hline \multicolumn{2}{|c|}{$1^{\circ} \mathrm{grau}$ compl. } & 13,52 & 8,67 & 14,96 & 9,42 & 8,24 & 7,82 & 12,28 & 8,76 & 7,43 & 6,18 & 15,86 & 10,83 & 13,10 & 9,82 & 18,41 & 5,81 & 13,27 & 10,48 & 14,33 & 9,09 \\
\hline \multicolumn{2}{|c|}{$\begin{array}{l}2^{\circ} \mathrm{grau} \\
\text { incomp. }\end{array}$} & 7,29 & 6,46 & 8,46 & 6,81 & 4,43 & 4,65 & 6,95 & 6,56 & 3,42 & 3,82 & 7,23 & \begin{tabular}{|l|}
5,21 \\
\end{tabular} & 5,91 & 4,64 & 6,04 & 27,68 & 8,27 & 7,14 & 9,92 & 10,33 \\
\hline \multicolumn{2}{|c|}{$2^{\circ}$ grau compl. } & 19,45 & 30,44 & 28,48 & 43,19 & 13,22 & 23,52 & 26,14 & 39,03 & 7,55 & 13,82 & 22,44 & 27,18 & 12,37 & 19,21 & 22,94 & 9,83 & 20,00 & 30,00 & 28,21 & 38,43 \\
\hline \multicolumn{2}{|c|}{$\begin{array}{l}\text { Superior } \\
\text { incomp. }\end{array}$} & 2,74 & 2,89 & 3,31 & 6,09 & 2,50 & 2,95 & 4,68 & 7,37 & $\mid 1,22$ & 2,52 & 4,70 & 5,31 & 3,44 & 4,64 & 6,49 & 35,54 & 3,13 & 2,38 & 4,82 & 13,22 \\
\hline \multicolumn{2}{|c|}{\begin{tabular}{|l|}
$\begin{array}{l}\text { Superior } \\
\text { compl. }\end{array}$ \\
\end{tabular}} & 7,27 & 12,76 & 7,67 & 12,90 & 8,60 & 12,42 & 11,56 & 18,46 & 5,98 & 12,93 & 19,87 & 38,58 & 11,20 & 24,39 & 14,88 & 0,00 & 0,13 & 14,29 & 9,40 & 14,88 \\
\hline \multicolumn{2}{|c|}{ Não informado } & 17,33 & 19,90 & 2,13 & 2,61 & 34,69 & 32,66 & 2,24 & 2,54 & 54,20 & 49,59 & 1,61 & 1,29 & 30,32 & 26,27 & 1,30 & 1,31 & 25,20 & 18,10 & 1,72 & 2,89 \\
\hline
\end{tabular}

Fonte: TSE - Tribunal Superior Eleitoral

Apesar de algumas variações do grau de instrução dos vereadores para o ano de 2004, as mulheres continuam apresentando instrução superior a dos homens e o Sul e Sudeste continuam se diferenciando das outras regiões como se pode notar pela Tabela 5 .

\section{Tabela 5}

Distribuição dos vereadores segundo o grau de instrução, por região e por sexo Brasil - 2004

\begin{tabular}{|c|c|c|c|c|c|c|c|c|c|c|}
\hline \multirow[t]{2}{*}{$\begin{array}{c}\text { Região, Sexo } \\
\text { Grau de Instrução }\end{array}$} & \multicolumn{2}{|c|}{ Norte } & \multicolumn{2}{|c|}{ Nordeste } & \multicolumn{2}{|c|}{ Sudeste } & \multicolumn{2}{|c|}{ Sul } & \multicolumn{2}{|c|}{ Centro-Oeste } \\
\hline & $\mathrm{H}$ & M & $\mathrm{H}$ & M & $\mathrm{H}$ & M & $\mathrm{H}$ & M & $\mathrm{H}$ & M \\
\hline Lê e escreve & 5,81 & 1,32 & 9,49 & 2,59 & 2,96 & 1,69 & 1,73 & 0,96 & 3,29 & 1,56 \\
\hline $1^{\circ}$ grau incomp. & 13,42 & 11,66 & 10,13 & 9,08 & 15,93 & 10,34 & 16,20 & 10,40 & 12,51 & 7,29 \\
\hline $1^{\circ}$ grau completo & 26,75 & 11,35 & 21,23 & 11,01 & 27,11 & 11,57 & 29,16 & 9,44 & 21,06 & 11,28 \\
\hline $2^{\circ}$ grau incomp. & 30,24 & 37,99 & 28,87 & 36,33 & 25,86 & 29,78 & 25,32 & 28,32 & 35,99 & 34,03 \\
\hline $2^{\circ}$ grau completo & 8,08 & 6,41 & 8,37 & 4,73 & 5,81 & 4,55 & 6,41 & 4,64 & 6,71 & 4,69 \\
\hline Superior incomp. & 9,04 & 20,72 & 15,12 & 28,30 & 18,00 & 35,10 & 14,51 & 39,20 & 13,48 & 31,94 \\
\hline Superior compl. & 5,93 & 10,53 & 6,17 & 7,71 & 3,99 & 6,89 & 5,69 & 6,56 & 6,31 & 8,85 \\
\hline Não informado & 0,14 & 0,00 & 0,61 & 0,25 & 0,00 & 0,00 & 0,99 & 0,48 & 0,65 & 0,35 \\
\hline
\end{tabular}

Fonte: TSE - Tribunal Superior Eleitoral

\footnotetext{
2 Não foi possível, nesta pesquisa, analisar a composição social da câmara dos vereadores e a composição social dos partidos.
} 
Para os dados sobre idade, os registros de 1996 são incompletos, e apenas para 2004 o TSE aperfeiçoou os critérios utilizados na coleta de dados, a fim de permitir uma referência mais adequada em relação à faixa etária dos vereadores. Os dados da Tabela 6 mostram que a maior concentração de vereadores está na faixa entre 30 e 40 anos e entre 40 e 50 anos. A comparação com dados relativos a períodos anteriores mostra que esse segmento da classe política sofreu rejuvenescimento.

Tabela 6

Distribuição dos vereadores por faixas de idade, por região Brasil - eleições de 1996, 2000 e 2004

\begin{tabular}{|l|c|c|c|c|c|c|c|c|c|c|c|c|c|c|c|}
\hline \multirow{2}{*}{ Idade } & Região & \multicolumn{3}{|c|}{ Norte \% } & \multicolumn{3}{|c|}{ Nordeste \% } & \multicolumn{3}{c|}{ Sudeste \% } & \multicolumn{3}{c|}{ Sul \% } & \multicolumn{2}{c|}{ Centro-Oeste \% } \\
\hline Ano & $\mathbf{1 9 9 6}$ & $\mathbf{2 0 0 0}$ & $\mathbf{2 0 0 4}$ & $\mathbf{1 9 9 6}$ & $\mathbf{2 0 0 0}$ & $\mathbf{2 0 0 4}$ & $\mathbf{1 9 9 6}$ & $\mathbf{2 0 0 0}$ & $\mathbf{2 0 0 4}$ & $\mathbf{1 9 9 6}$ & $\mathbf{2 0 0 0}$ & $\mathbf{2 0 0 4}$ & $\mathbf{1 9 9 6}$ & $\mathbf{2 0 0 0}$ & $\mathbf{2 0 0 4}$ \\
\hline De 20 a 30 anos & 0,70 & 5,12 & 1,78 & 0,26 & 6,26 & 3,35 & 0,09 & 6,58 & 1,14 & 0,00 & 3,89 & 0,84 & 0,09 & 4,82 & 1,08 \\
\hline De 30 a 40 anos & 1,60 & 31,41 & 19,60 & 1,18 & 26,28 & 16,29 & 0,37 & 27,84 & 13,01 & 0,04 & 25,18 & 15,74 & 0,36 & 33,27 & 18,71 \\
\hline De 40 a 50 anos & 1,74 & 32,68 & 43,21 & 2,15 & 37,30 & 37,44 & 0,28 & 40,40 & 34,23 & 0,20 & 44,64 & 41,92 & 0,88 & 41,99 & 45,38 \\
\hline De 50 a 60 anos & 0,97 & 13,20 & 25,84 & 1,55 & 20,44 & 27,06 & 0,11 & 17,06 & 35,07 & 0,25 & 20,57 & 29,63 & 0,24 & 16,39 & 27,74 \\
\hline De 60 a 70 anos & 0,33 & 2,63 & 6,90 & 0,31 & 7,80 & 11,72 & 0,27 & 5,67 & 11,93 & 0,16 & 4,89 & 9,85 & 0,12 & 2,60 & 5,81 \\
\hline 80 anos ou mais & 0,30 & 0,18 & 1,78 & 0,18 & 1,58 & 2,29 & 0,00 & 1,21 & 3,24 & 0,02 & 0,84 & 1,26 & 0,00 & 0,36 & 0,65 \\
\hline Não consta & 94,65 & 14,78 & 0,89 & 94,39 & 0,35 & 1,84 & 98,87 & 1,24 & 1,38 & 99,33 & 0,00 & 0,76 & 98,31 & 0,58 & 0,65 \\
\hline
\end{tabular}

Fonte: TSE - Tribunal Superior Eleitoral

Quanto à ocupação, a quase totalidade dos vereadores é constituída de trabalhadores rurais, servidores públicos, empresários da indústria, do comércio e de serviços, trabalhadores de atividades não-manuais de rotina, profissionais de escritório, profissionais liberais e, sendo que em 2004, aparecem os empresários do setor primário ${ }^{3}$. O ordenamento dessas ocupações mostra diferenças regionais, expostas na Tabela 7. A mais importante refere-se à região Sudeste para 2000, onde é significativo o número de vereadores com profissões liberais, acompanhando os dados sobre o grau de instrução mais elevado da região.

\footnotetext{
${ }^{3}$ As categorias ocupacionais foram estabelecidas a partir dos critérios fixados por Nelson do Valle Silva e discutidos em Scallon (1999), dentre mais de cem ocupações identificadas pelo TSE.
} 
Em 2004, os vereadores com profissões liberais passam a ter importância em todas as regiões, assim como os empresários da indústria, comércio e serviços e os servidores públicos. Interessante notar que os trabalhadores rurais dão lugar aos empresários do setor primário, no Norte e no Centro-Oeste. Os trabalhadores não-manuais de rotina e os profissionais de escritório perdem importância na representação para vereança.

\section{Tabela 7}

\section{Distribuição dos vereadores segundo ocupação, por região}

\section{Brasil - 1996 e 2000}

\begin{tabular}{|c|c|c|c|c|c|c|c|c|c|c|c|c|c|c|c|c|}
\hline \multirow{2}{*}{ Profissões } & \multirow{2}{*}{$\begin{array}{c}\text { Região } \\
\text { Ano } \\
\end{array}$} & \multicolumn{3}{|c|}{ Norte \% } & \multicolumn{3}{|c|}{ Nordeste \% } & \multicolumn{3}{|c|}{ Sudeste $\%$} & \multicolumn{3}{|c|}{ Sul $\%$} & \multicolumn{3}{|c|}{ Centro-Oeste \% } \\
\hline & & 1996 & 2000 & 2004 & 1996 & 2000 & 2004 & 1996 & 2000 & 2004 & 1996 & 2000 & 2004 & 1996 & 2000 & 2004 \\
\hline \multicolumn{2}{|l|}{ Aposentado } & 0,00 & 0,48 & 2,06 & 0,00 & 1,54 & 1,90 & 0,00 & 3,51 & 3,60 & 0,00 & 2,59 & 2,19 & 0,60 & 0,77 & 1,08 \\
\hline \multicolumn{2}{|c|}{ Artesãos e Artistas } & 0,10 & 0,04 & 0,00 & 0,04 & 0,13 & 0,00 & 0,05 & 0,44 & 0,12 & 0,07 & 0,67 & 0,00 & 1,00 & 0,19 & 0,00 \\
\hline \multicolumn{2}{|c|}{$\begin{array}{l}\text { Dirigentes Administrativos de } \\
\text { Alto Nível }\end{array}$} & 1,80 & 1,16 & 3,70 & 0,63 & 1,30 & 8,20 & 1,17 & 2,76 & 7,67 & 1,82 & 2,08 & 8,92 & 5,89 & 5,29 & 5,38 \\
\hline \multicolumn{2}{|c|}{$\begin{array}{l}\text { Empresários na Indústria, } \\
\text { Comércio e Serviços }\end{array}$} & 10,19 & 8,34 & 16,46 & 5,49 & 9,95 & 16,29 & 7,14 & 14,95 & 20,74 & 11,73 & 15,81 & 21,46 & 15,46 & 12,51 & 20,86 \\
\hline \multicolumn{2}{|c|}{$\begin{array}{l}\text { Empresários no Setor } \\
\text { Primário }\end{array}$} & 7,39 & 2,47 & 8,85 & 6,74 & 3,36 & 5,58 & 5,10 & 4,09 & 6,41 & 5,38 & 2,52 & 3,28 & 7,94 & 5,81 & 11,40 \\
\hline \multicolumn{2}{|c|}{$\begin{array}{l}\text { Funções Administrativas } \\
\text { (execução) }\end{array}$} & 1,30 & 0,00 & 0,41 & 0,55 & 0,06 & 0,45 & 0,80 & 0,49 & 0,48 & 4,47 & 0,72 & 0,59 & 1,09 & 0,08 & 0,43 \\
\hline \multicolumn{2}{|c|}{ Funções Religiosas } & 0,33 & 0,22 & 0,62 & 0,01 & 0,08 & 0,39 & 0,03 & 0,56 & 0,60 & 0,04 & 0,30 & 0,25 & 0,30 & 0,30 & 0,00 \\
\hline \multicolumn{2}{|c|}{$\begin{array}{l}\text { Membros do Poder } \\
\text { legislativo } \\
\end{array}$} & 12,67 & 4,72 & 1,44 & 9,21 & 4,33 & 2,29 & 4,43 & 4,79 & 1,80 & 4,82 & 2,81 & 1,35 & 1,87 & 3,24 & 3,44 \\
\hline \multicolumn{2}{|c|}{$\begin{array}{l}\text { Não-manual de Rotina e } \\
\text { Funções de Escritório }\end{array}$} & 8,52 & 7,35 & 0,00 & 4,78 & 7,25 & 0,00 & 3,46 & 9,59 & 0,12 & 5,84 & 8,33 & 0,00 & 8,48 & 11,79 & 0,00 \\
\hline \multicolumn{2}{|c|}{ Profissionais Liberais } & 25 & 3,05 & 3,17 & 5,82 & 60 & 2,04 & 4,09 & 0,48 & 20,20 & 8,29 &, 41 & 15,99 & 7,49 &, 36 & 17,85 \\
\hline \multicolumn{2}{|c|}{$\begin{array}{l}\text { Publicitário, Locutores, } \\
\text { Radialista, Op. de Câmera, } \\
\text { Jornalista }\end{array}$} & 0,30 & 0,32 & 0,41 & 0,24 & 0,25 & 0,50 & 0,19 & 0,71 & 0,42 & 0,26 & 0,60 & 0,67 & 0,51 & 0,89 & 0,22 \\
\hline \multicolumn{2}{|c|}{ Servidores Públicos } & 4,11 & 9,90 & 21,60 & 0,69 & 9,53 & 19,20 & 0,82 & 11,72 & 18,94 & 3,75 & 8,28 & 21,89 & 14,07 & 12,59 & 19,14 \\
\hline \multicolumn{2}{|c|}{$\begin{array}{l}\text { Técnicos Administrativos na } \\
\text { Indústria, Comércio e } \\
\text { Serviços }\end{array}$} & 1,80 & 3,92 & 2,26 & 1,08 & 6,58 & 1,56 & 0,85 & 4,43 & 1,38 & 1,04 & 5,35 & 2,44 & 2,90 & 3,16 & 1,72 \\
\hline \multicolumn{2}{|c|}{$\begin{array}{l}\text { Técnicos Artistas e Serviços } \\
\text { de Trabalho Manual }\end{array}$} & 0,00 & 3,60 & 0,00 & 0,02 & 4,24 & 0,00 & 0,01 & 3,95 & 0,06 & 0,00 & 2,67 & 0,17 & 4,02 & 3,65 & 0,00 \\
\hline \multicolumn{2}{|c|}{$\begin{array}{l}\text { Trabalhador no Serviço } \\
\text { Doméstico }\end{array}$} & 1,97 & 1,41 & 0,41 & 1,55 & 1,38 & 0,33 & 0,69 & 1,29 & 0,24 & 0,93 & 1,34 & 0,08 & 4,14 & 1,83 & 0,65 \\
\hline \multicolumn{2}{|c|}{$\begin{array}{l}\text { Trabalhadores Manuais da } \\
\text { Indústria }\end{array}$} & 9,32 & 0,80 & 0,41 & 6,22 & 0,59 & 1,28 & 7,13 & 2,85 & 0,96 & 9,23 & 2,44 & 0,34 & 3,29 & 2,10 & 0,43 \\
\hline \multicolumn{2}{|c|}{$\begin{array}{l}\text { Trabalhadores Manuais em } \\
\text { Serviços Gerais } \\
\end{array}$} & 0,77 & 2,89 & 0,00 & 0,26 & 2,49 & 0,00 & 0,39 & 4,60 & 0,00 & 0,43 & 4,06 & 0,00 & 5,28 & 4,51 & 0,00 \\
\hline \multicolumn{2}{|c|}{ Trabalhadores Rurais } & 5,51 & 15,16 & 4,94 & 6,55 & 21,46 & 9,43 & 3,96 & 12,23 & 9,47 & 14,56 & 22,55 & 13,13 & 10,93 & 13,40 & 9,68 \\
\hline \multicolumn{2}{|l|}{ Outros } & 0,23 & 2,53 & 9,67 & 1,49 & 2,18 & 5,64 & 0,61 & 6,15 & 5,64 & 0,47 & 7,19 & 4,71 & 2,81 & 3,68 & 5,16 \\
\hline \multicolumn{2}{|l|}{ Não Consta } & 27,41 & 31,65 & 13,58 & 48,62 & 16,69 & 4,91 & 59,07 & 0,42 & 1,14 & 26,86 & 3,30 & 2,53 & 1,93 & 6,89 & 2,58 \\
\hline
\end{tabular}

Fonte: TSE - Tribunal Superior Eleitoral 
O fato de os trabalhadores rurais estarem representados de modo tão significativo sugere a importância desse segmento em cidades de pequeno porte e em regiões onde a população rural é marcante ${ }^{4}$. É também significativo o aparecimento de empresários do setor primário no ano de 2004.

Tabela 8

Segmentos ocupacionais mais importantes para o recrutamento de vereadores Brasil - 2000 e 2004

\begin{tabular}{|c|c|c|c|c|c|c|c|c|c|c|c|c|}
\hline & \multicolumn{2}{|c|}{ Norte } & \multicolumn{2}{|c|}{ Nordeste } & \multicolumn{2}{|c|}{ Sudeste } & \multicolumn{2}{|c|}{ Sul } & \multicolumn{2}{|c|}{ Centro-Oeste } & \multicolumn{2}{|c|}{ Total } \\
\hline & 2000 & 2004 & 2000 & 2004 & 2000 & 2004 & 2000 & 2004 & 2000 & 2004 & 2000 & 2004 \\
\hline $\begin{array}{l}\text { Empresários do setor } \\
\text { primário }\end{array}$ & & 8,85 & & & & & & & & 11,40 & & 6,11 \\
\hline $\begin{array}{l}\text { Empresários na Indústria, } \\
\text { Comércio e Serviços }\end{array}$ & 8,34 & 16,46 & 9,95 & 16,29 & 14,95 & 20,74 & 15,81 & 21,46 & 12,51 & 20,86 & 12,53 & 14,30 \\
\hline $\begin{array}{l}\text { Não-manual de Rotina e } \\
\text { Profissionais de Escritório }\end{array}$ & 7,35 & & 7,25 & & & & 8,33 & & 11,79 & & 8,47 & \\
\hline Profissionais Liberais & & 13,17 & & 22,04 & 10,48 & 20,20 & & 15,99 & & 17,85 & 7,34 & 8,19 \\
\hline Servidores Públicos & 9,90 & 21,60 & 9,53 & 19,20 & 11,73 & 18,94 & 8,28 & 21,89 & 12,59 & 19,14 & 10,16 & 18,07 \\
\hline Trabalhadores Rurais & 15,16 & & 21,46 & 9,43 & 12,23 & 9,47 & 22,55 & 13,13 & 13,40 & & 17,82 & 14,08 \\
\hline
\end{tabular}

Fonte: TSE - Tribunal Superior Eleitoral

Os funcionários públicos continuam sendo uma fonte importante de recrutamento para candidatos à vereança ${ }^{5}$. Na categoria "empregados em atividades não-manuais" estão, basicamente, os bancários e técnicos em geral, que diminuem o grau de representação nas eleições de 2004. Na categoria "empresários" não foram levados em conta a dimensão do empreendimento nem o ramo de atividade. A dimensão desta categoria nas bancadas partidárias não pôde ser observada, o que nos impossibilita correlacionar os perfis de carreira. Não foi possível estabelecer comparações com a literatura que discute a origem social dos membros do Congresso Nacional e assembléias legislativas, uma vez que não foi possível relacionar indicadores socioeconômicos com a filiação partidária dos vereadores (RODRIGUES, 2002; MESSEMBERG, 2002; CORADINI, 2001; SAMUELS, 1998; MARENCO DOS SANTOS, 1997; SANTOS, 2001).

As tão comentadas bancadas dos comunicadores e dos profissionais religiosos não são, na verdade, tão representativas nas câmaras municipais quanto aponta uma parte da literatura sobre o tema. A presença dos comunicadores é maior nas câmaras das regiões Sudeste e Centro-Oeste; o número de vereadores ligados a atividades religiosas também é mais expressivo nas regiões Norte e Sudeste.

\footnotetext{
${ }^{4}$ As diferenças encontradas entre estados de uma mesma região apontam para fortes desníveis intra. regionais.

5 Dentro dessa categoria não foi possível identificar os professores, pois os dados do TSE não puderam ser desagregados dos dados totais.
} 
Os dados sobre o desempenho dos partidos nas eleições para o legislativo local - inclusive os relativos a 2004 - completam a descrição do perfil dos vereadores brasileiros, como mostram as tabelas seguintes.

Tabela 9

Vereadores eleitos, por partido

Brasil - 1996, 2000 e 2004

\begin{tabular}{|l|c|c|c|c|c|c|}
\hline Partidos & $\mathbf{1 9 9 6}$ & $\mathbf{\%}$ & $\mathbf{2 0 0 0}$ & $\mathbf{\%}$ & $\mathbf{2 0 0 4}$ & $\%$ \\
\hline PPB (PP) & 6.238 & 13,14 & 6.805 & 12,27 & 54,57 & 10,53 \\
\hline PDT & 3.311 & 6,97 & 3.332 & 6,01 & 3.252 & 6,28 \\
\hline PT & 1.546 & 3,26 & 2.234 & 4,03 & 3.679 & 7,10 \\
\hline PTB & 3.029 & 6,38 & 4.450 & 8,02 & 4.176 & 8,06 \\
\hline PMDB & 11.389 & 23,99 & 10.647 & 19,19 & 7.399 & 14,28 \\
\hline PSTU & 0 & 0,00 & 2 & 0,00 & 902 & 1,74 \\
\hline PSL & 260 & 0,55 & 429 & 0,77 & 506 & 0,98 \\
\hline PST & 148 & 0,31 & 359 & 0,65 & 0 & 0,00 \\
\hline PTN & 25 & 0,05 & 80 & 0,14 & 0 & 0,00 \\
\hline PSC & 561 & 1,18 & 646 & 1,16 & 724 & 1,40 \\
\hline PCB & 0 & 0,00 & 2 & 0,00 & 60 & 0,12 \\
\hline PL & 2.350 & 4,95 & 2.490 & 4,49 & 3.806 & 7,34 \\
\hline PPS & 384 & 0,81 & 2.292 & 4,13 & 2.745 & 5,30 \\
\hline PFL & 8.164 & 17,19 & 9.050 & 16,31 & 6.076 & 11,73 \\
\hline PAN & 2 & 0,00 & 29 & 0,05 & 84 & 0,16 \\
\hline PSDC & 55 & 0,12 & 212 & 0,38 & 826 & 1,59 \\
\hline PRTB & 21 & 0,04 & 198 & 0,36 & 228 & 0,44 \\
\hline PCO & 0 & 0,00 & 0 & 0,00 & 12 & 0,02 \\
\hline PGT & 3 & 0,01 & 28 & 0,05 & 0 & 0,00 \\
\hline PSN/PHS & 7 & 0,01 & 110 & 0,20 & 346 & 0,67 \\
\hline PMN & 332 & 0,70 & 318 & 0,57 & 519 & 1,00 \\
\hline PRN & 51 & 0,11 & 56 & 0,10 & 0 & 0,00 \\
\hline PSB & 956 & 2,01 & 1.553 & 2,80 & 1.805 & 3,48 \\
\hline PSD & 1.173 & 2,47 & 1.472 & 2,65 & 0 & 0,00 \\
\hline PV & 164 & 0,35 & 310 & 0,56 & 782 & 1,51 \\
\hline PRP & 340 & 0,72 & 391 & 0,70 & 596 & 1,15 \\
\hline PSDB & 6.754 & 14,22 & 7.690 & 13,86 & 6.566 & 12,67 \\
\hline PRONA & 33 & 0,07 & 26 & 0,05 & 131 & 0,25 \\
\hline PC do B & 0,18 & 138 & 0,25 & 273 & 0,53 \\
\hline PT do B & 07.482 & 100,00 & 55.483 & 100,00 & 51.819 & 100,00 \\
\hline PTC & 0,21 & 134 & 0,24 & 317 & 0,61 \\
\hline Total & 0,00 & 0 & 0,00 & 310 & 0,60 \\
\hline & 100 & & & & & \\
\hline
\end{tabular}

* Nas eleições de 2000, houve um aumento de $17 \%$ das cadeiras; em 2004, o número de vereadores foi reduzido pelo TSE.

Fonte: TSE - Tribunal Superior Eleitoral 
O número de partidos com representação local indica a fragmentação partidária no Brasil, com efeitos marcantes no processo eleitoral municipal, bem como na atuação das câmaras municipais e na constituição dos interesses dos vereadores de situação e de oposição.

Os dados da Tabela 9 mostram que o PMDB tem sido o partido que mais elege vereadores no país, apesar de ter havido uma queda na eleição de 2004, refletindo uma significativa capilaridade e a importância da organização partidária. As outras forças partidárias bem representadas são o PFL, o PSDB e o PPB (PP), partidos que também sofreram perdas significativas de participação na eleição de 2004. Ao mesmo tempo, tiveram aumento as bancadas de vereadores eleitos pelo PT, PL, PPS e PSB. A maior competição neste nível de representação parece não estar ligada apenas à diminuição do número de vereadores estipulada pelo TSE e ao conseqüente esforço dos partidos para ampliar as suas áreas de votação. Em tudo isso, a novidade é o crescimento da bancada de vereadores do PV, que passou de 0,56\%, em 2000, para 1,51\%, em 2004.

Devem-se ressaltar as magnitudes eleitorais regionais. Os estados do Norte e do Centro-Oeste são aqueles com o menor número de municípios e, conseqüentemente, com o menor número de vereadores. A Tabela 10 mostra a dimensão desta diferença com base no tamanho dos eleitorados.

\section{Tabela 10}

Distribuição dos votos para vereador, por região

Brasil - 1996, 2000 e 2004

\begin{tabular}{|l|c|c|c|c|c|c|}
\hline Região & $\mathbf{1 9 9 6}$ & $\mathbf{\%}$ & $\mathbf{2 0 0 0}$ & $\mathbf{\%}$ & $\mathbf{2 0 0 4}$ & $\mathbf{\%}$ \\
\hline Norte & 3.881 .584 & 5,46 & 5.512 .649 & 6,37 & 6.153 .128 & 6,98 \\
\hline Nordeste & 17.836 .749 & 25,13 & 22.737 .176 & 26,32 & 24.265 .682 & 27,53 \\
\hline Sudeste & 32.196 .381 & 45,37 & 38.885 .744 & 44,99 & 38.058 .194 & 43,18 \\
\hline Sul & 12.670 .980 & 17,85 & 13.948 .644 & 16,15 & 14.435 .036 & 18,26 \\
\hline Centro-Oeste & 4.392 .527 & 6,18 & 5.329 .433 & 6,17 & 5.209 .640 & 5,91 \\
\hline Total & 70.978 .221 & 100,00 & 86.413 .643 & 100,00 & 88.121 .680 & 100,00 \\
\hline
\end{tabular}

Fonte: TSE - Tribunal Superior Eleitoral

A análise regional dos resultados partidários para as câmaras municipais mostra algumas diferenças importantes (Tabela 11) ${ }^{6}$.

\footnotetext{
${ }^{6}$ Nossa análise não se deteve nas singularidades dos estados, mas apenas nas diferenças regionais.
} 
O PMDB foi o partido com o maior número de vereadores eleitos nas regiões Norte, Sudeste, Sul e Centro-Oeste nas eleições 1996/2000. Nas eleições de 2004, perde representação significativa no Norte e no Sudeste; apesar de crescer na região Centro-Oeste não consegue ultrapassar o PSDB. Na região Nordeste, o PFL reúne uma bancada maior do que a do PMDB. Nas outras regiões, os bons resultados eleitorais obtidos pelo PFL apontam para uma capilaridade a ser considerada.

O PSDB foi o segundo partido nas eleições 1996/2000, com maior votação para o legislativo municipal nos estados das regiões Norte, Nordeste e Sudeste, perdendo para o PFL nas regiões Sul e Centro-Oeste. Nas eleições de 2004, o PSDB foi o partido que mais elegeu vereadores no Norte, no Sudeste e no Centro-Oeste.

O PPB (PP) se sobressai nas regiões Norte e Sul em 1996 e em 2000, e Centro-Oeste em 2004. O PTB teve um desempenho mais homogêneo em todas as regiões, conseguindo aumentar significativamente sua votação na região CentroOeste, na eleição de 2004.

Para o PT, os desempenhos mais baixos foram localizados nas regiões Nordeste e Centro-Oeste nas eleições de 1996 e 2000; em 2004, o desempenho foi mais equilibrado em todas as regiões.

O PFL, o PPS e o PSB mostraram um aumento tendencial do número de vereadores nas eleições de 1996 e 2000. Em 2004, o PFL só cresceu na região Centro-Oeste.

Focalizando as regiões, em 2004 a região Nordeste manteve a tendência de votação das outras eleições, e o Sul foi a região que mais diferenças apresentou. Nele, o PSTU $(8,12 \%)$ e o PSDC $(4,12 \%)$ conseguiram ultrapassar a votação do PPS e PSB. Apesar da queda significativa de votos do PMDB e do PP, continuaram sendo os partidos mais votado. O PDT encontrou sua maior expressão nesta região.

Quando confrontadas a resultados eleitorais para câmaras municipais, as análises que apontam para a tendência de os partidos de direita obterem melhores resultados nas regiões menos desenvolvidas e os partidos de centro e de esquerda serem mais bem sucedidos nas regiões mais desenvolvidas revelam-se insuficientes.

Da mesma forma, as teses comumente divulgadas na literatura política sobre o Brasil, relativas às constantes migrações partidárias, que apontam o movimento das lideranças locais para acompanhar os governadores (o ultrapresidencialismo estadual), às estratégias políticas personalistas e à desvalorização dos partidos, precisam ser repensadas a partir dos resultados dos legislativos locais. Os dados mostram que alguns partidos mantêm um padrão regular de votação. Como explicar, por exemplo, que nestes dez anos o PMDB continue sendo o partido que mais vereadores elege no Brasil? 
A análise aprofundada e desvinculada de prejulgamentos sobre a atuação das câmaras municipais e dos vereadores, seja nos processos eleitoral e partidário, seja no processo decisório local e suas formas de relacionamento com os executivos locais, revela o significado político desta esfera de atuação, que não se molda apenas pela troca de lealdades ou pela distribuição de benefícios, características da prática clientelista.

Tabela 11

Vereadores eleitos e partidos mais votados, por região Brasil - 1996-2000-2004

\begin{tabular}{|c|c|c|c|c|c|c|c|c|c|c|c|c|c|c|c|}
\hline \multirow{2}{*}{$\begin{array}{l}\text { Região } \\
\text { Partidos }\end{array}$} & \multicolumn{3}{|c|}{ Norte \% } & \multicolumn{3}{|c|}{ Nordeste $\%$} & \multicolumn{3}{|c|}{ Sudeste $\%$} & \multicolumn{3}{|c|}{ Sul $\%$} & \multicolumn{3}{|c|}{ Centro-Oeste \% } \\
\hline & 1996 & 2000 & 2004 & 1996 & 2000 & 2004 & 1996 & 2000 & 2004 & 1996 & 2000 & 2004 & 1996 & 2000 & 2004 \\
\hline PDT & 4,56 & 4,04 & 4,97 & 5,04 & 4,39 & 4,53 & 4,43 & 4,90 & 5,92 & 15,70 & 9,54 & 10,60 & 0,50 & 0,70 & 4,53 \\
\hline PFL & 19,99 & 0,73 & 11,32 & 22,00 & 19,24 & 16,51 & 19,47 & 13,92 & 11,89 & 12,30 & 12,86 & 4,88 & 6,61 & 30 & 0,57 \\
\hline PL & 2,98 & 5,58 & 9,60 & 5,97 & 5,19 & 7,71 & 5,21 & 4,70 & 8,86 & 1,33 & 0,94 & 2,20 & 4,47 & 2,70 & 11,25 \\
\hline PMDB & 19,62 & 25,05 & 11,78 & 18,49 & 17,12 & 12,89 & 15,98 & 17,72 & 13,49 & 30,13 & 25,76 & 18,45 & 19,24 & 11,38 & 14,33 \\
\hline PPB (PP) & 17,04 & 14,20 & 8,53 & 8,48 & 8,98 & 8,50 & 9,72 & 7,65 & 7,68 & 22,62 & 23,20 & 19,40 & 8,01 & 5,96 & 10,39 \\
\hline PPS & 0,92 & 2,69 & 5,40 & 1,91 & 5,07 & 5,32 & 0,78 & 5,34 & 5,69 & 0,08 & 1,52 & 3,26 & 0,03 & 2,52 & 8,89 \\
\hline PSB & 2,72 & 2,05 & 3,92 & 4,42 & 3,93 & 4,80 & 1,96 & 4,07 & 3,36 & 0,45 & 1,52 & & 0,11 & 0,20 & 2,29 \\
\hline PSDB & 14,64 & 12,67 & 13,07 & 15,26 & 15,02 & 11,58 & 21,58 & 15,45 & 15,57 & 6,30 & 9,69 & 8,84 & 5,95 & 8,05 & 15,59 \\
\hline PT & 3,45 & 4,16 & 9,77 & 1,68 & 1,94 & 4,33 & 3,15 & 4,89 & 7,69 & 5,04 & 5,95 & 8,97 & 1,19 & 1,13 & 8,24 \\
\hline PTB & 6,94 & 7,29 & 9,15 & 6,08 & 6,97 & 7,33 & 7,87 & 9,28 & 10,01 & 4,80 & 5,42 & 6,17 & 1,32 & 1,90 & 7,44 \\
\hline $\begin{array}{l}\text { Total de } \\
\text { Vereadores }\end{array}$ & .455 & 4.862 & 4.186 & 4.687 & 17.823 & 16.53 & 15.518 & 18.67 & 15.842 & 11.11 & 12.135 & $10.967 \mid$ & 1.710 & 1.986 & 4.285 \\
\hline
\end{tabular}

Fonte: TSE - Tribunal Superior Eleitoral

\section{A percepção dos legislativos de Santa Catarina e de São Paulo sobre o processo decisório local}

A incorporação dos municípios à federação brasileira, determinada na Constituição de 1988, trouxe mudanças na organização e no funcionamento dos governos locais, devidas à descentralização e à transferência de responsabilidade decisória para as unidades subnacionais. O município recebeu a maior parcela das transferências constitucionais e foi o principal destinatário da descentralização de competências e atribuições na área social. 
Descentralização e participação tornaram-se conceitos fundamentais para entender a revalorização da política e das instituições do governo local. A expressão fundamental dessas mudanças institucionais consubstancia-se nos conselhos municipais legalmente criados, e que se constituem como arena participativa, definidora do processo decisório.

A entrada em cena dos conselhos municipais, canais de participação da sociedade na gestão pública, e a existência de um novo padrão de governo municipal, baseado no princípio da governança democrática, que supõe a interação entre governo e sociedade em novos arranjos institucionais, praticamente não levam em conta o papel do legislativo local, referendando o consenso quase geral de que as câmaras municipais constituem um apêndice do poder executivo.

As pesquisas sobre o legislativo local, surgidas no final da década de 1990, apontam para uma instituição clientelista por excelência e homologadora das decisões do prefeito, nas quais as transferências de recursos individualizados garantem a reeleição dos vereadores e a permanência de um círculo vicioso da política local, regido pelo clientelismo, pelo mandonismo, pelo paternalismo e pela hipertrofia do poder executivo, com relações de dependência político-partidária dos governos locais para com os governos estaduais (SOUZA, 2004).

Pesquisas apontam para um círculo virtuoso da política local, segundo o qual a delegação e a transferência de competências ao governo local e a incorporação da sociedade civil ao processo de formulação e gestão das políticas públicas, especialmente das políticas sociais, levam a decisões mais racionais das políticas públicas locais e aumentam sua qualidade, eficiência, eficácia e efetividade (AVRITZER, 2002) ${ }^{7}$. Duas questões se colocam, relacionadas a estas vertentes de análise:

1) a falta de referências às condições gerais que dão suporte à transformação do papel do governo em âmbito local, condições vinculadas à estrutura fiscal federativa, às desigualdades econômicas, sociais e regionais entre municípios e à dinâmica local resultante dos interesses e das forças políticas locais, assim como, fundamentalmente, das diferenças entre rural e urbano, que marcam significativamente as práticas políticas locais. Nos estados e municípios com características predominantemente rurais, a política continua marcada pelo clientelismo e pela pequena capacidade de renovação das elites políticas locais. Nos estados e municípios com características predominantemente urbanas, as elites locais mostraram maior capacidade de renovação; nelas, a exposição à

\footnotetext{
7 Para alguns autores, a transição caracteriza-se por um hibridismo de interesses que combina formatos corporativos, clientelistas, pluralistas e conexões informais, com estilos predatórios e universalistas, em um processo de reordenamento dos interesses políticos que ainda não esgotou suas possibilidades (ver SANTOS, 1999).
} 
competição política interfere nas relações de corte clientelista, e há mais espaço para a autonomia decisória e para a adoção de decisões mais universalistas e menos clientelistas;

2) a virtuosidade do sistema participativo contrasta com o sistema representativo. Os municípios dotados de poder efetivo podem representar um incentivo à participação política, enquanto corretivo à democracia representativa. $A$ participação da sociedade civil nos negócios públicos minimizaria o patrimonialismo e a privatização da política, e enfatizaria os procedimentos participativos, em detrimento da qualidade da decisão e da representação. O círculo vicioso do sistema representativo estaria relacionado ao sistema eleitoral e ao sistema partidário, favoreceria o individualismo apartidário, o baixo prestígio do partido, a troca constante de legendas e a lista aberta, que caracterizariam especialmente a lógica da disputa política dos legislativos locais.

Estas duas lógicas perpassam as discussões sobre democracia no Brasil, especialmente sobre o papel do poder local no processo de aperfeiçoamento democrático.

Esta análise se completa com a percepção dos atores do executivo e do legislativo sobre estes novos arranjos institucionais locais, sobre estas novas formas de organização da sociedade civil, que interferem no relacionamento entre estes dois poderes.

Os dados apresentados fazem parte de uma pesquisa realizada entre 2001 e 2003, com prefeitos e presidentes de câmara de 42 municípios de São Paulo (SE), 19 municípios de Santa Catarina (S) e 12 municípios de Alagoas (NE) ${ }^{8}$.

Sobre os municípios estudados, cabe descrever alguns fatores que orientaram sua escolha:

1) o tamanho dos municípios-sede das divisões regionais. Para o estado de Alagoas, excetuando a capital (Maceió), apenas dois dos doze municípios-sede (Palmeira dos Índios e União dos Palmares) têm mais de 50 mil habitantes. Para o estado de Santa Catarina, excetuando a capital (Florianópolis), dez dos dezenove municípios-sede têm mais de 50 mil habitantes: Chapecó, Concórdia, Canoinhas, São Bento do Sul, Joinville, Lages, Blumenau, Itajaí, Tubarão, Criciúma. Desses dez, seis municípios têm mais de 100 mil habitantes. Para o estado de São Paulo, excetuando a capital (São Paulo), 37 dos 42 municípios-sede têm mais de 50 mil habitantes, e 20 municípios têm mais de 100 mil habitantes;

\footnotetext{
${ }^{8}$ Maria Teresa M.Kerbauy, Descentralização, Clivagens Regionais e Elites Políticas Locais: um estudo comparado, 2001-2003, pesquisa financiada pelo CNPq.
} 
2) a evolução do número de municípios. Entre 1988 e 1995, Alagoas foi um dos estados que menos criou municípios. Tinha 97 municípios em 1988 e 102 em 1995. Santa Catarina mostra uma situação intermediária, pois de 199 municípios, em 1988, passou para 287, em 1995. Para uma comparação inicial, São Paulo contava com 572 municípios em 1988 e passou a ter 636 municípios em 1995. A maior parte das unidades municipais concentra-se em Minas Gerais, São Paulo, Rio Grande do Sul e Paraná;

3) o tamanho da população urbana e rural. Segundo os dados preliminares do IBGE, o estado de Alagoas tinha 46,96\% de sua população na zona rural; o estado de Santa Catarina tinha $27,06 \%$ de sua população na zona rural; e o estado de São Paulo, apenas 0,70\% de sua população estava na zona rural;

4) distribuição de matrículas na educação fundamental municipal. A descentralização da educação é a política pública com maior visibilidade. Daí por que optamos por comparar os dados sobre matrícula. Segundo o $2^{\circ}$ Balanço do Fundef, Alagoas tinha, em 1999, 72,9\% das matrículas no ensino fundamental municipal, Santa Catarina contava com 40,5\% das matrículas no ensino fundamental e São Paulo, 25,8\% das matrículas no ensino fundamental municipal;

5) os estados escolhidos representam as regiões que têm o maior percentual no Fundo de Participação dos Municípios (FPM): Nordeste tem 35\%, Sudeste tem $31 \%$ e Sul tem 18\%, ficando para o Centro-Oeste $7 \%$ e $9 \%$ para o Norte. O critério adotado para a distribuição do FPM nas grandes cidades e capitais estaduais é a renda. Nos municípios com menos de 156.216 habitantes, o critério considerado é a relação entre o tamanho da população e a quantidade de recursos.

Para os municípios de São Paulo, os dados sobre a composição da população, a taxa de urbanização e o volume do eleitorado destes municípios apontam para um grande número (19) de cidades com mais de 100.000 habitantes, com alta taxa de urbanização e um número elevado de eleitores. Graças ao crescimento do eleitorado, os municípios de Bauru, Campinas, Piracicaba, Ribeirão Preto, Santos, São José do Rio Preto, São José dos Campos e Sorocaba alcançaram as condições mínimas exigidas para a realização do segundo turno, quando necessário, nas eleições municipais ${ }^{9}$.

\footnotetext{
9 Bauru e São José do Rio Preto alcançaram nas eleições de 2004 o número de eleitores (200.000) considerados necessários caso fosse preciso realizar o segundo turno. Dos questionários enviados para os municípios de São Paulo, 20 do executivo e 19 do legislativo foram devolvidos devidamente preenchidos; dos questionários enviados para os municípios de Santa Catarina, quatro do executivo e oito do legislativo foram devolvidos devidamente preenchidos.
} 
Tabela 12

Amostra dos municípios de São Paulo:

população, taxa de urbanização e eleitorado, em 2000

\begin{tabular}{|l|c|c|c|}
\hline Municípios & População & $\begin{array}{c}\text { Taxa de } \\
\text { Urbanização }\end{array}$ & Eleitorado \\
\hline Andradina (L) & 55.161 & 91,02 & 38.970 \\
\hline Araçatuba (L) & 169.240 & 97,16 & 115.043 \\
\hline Barretos (L) & 103.874 & 95,53 & 68.239 \\
\hline Bauru (L e E) & 315.835 & 98,40 & 195.967 \\
\hline Botucatu (L) & 108.112 & 94,70 & 68.389 \\
\hline Bragança Paulista (E e L) & 124.888 & 89,98 & 79.530 \\
\hline Campinas (L) & 967.321 & 96,17 & 624.527 \\
\hline Cruzeiro (E) & 73.469 & 96,40 & 50.157 \\
\hline Dracena (E) & 40.479 & 90,55 & 30.360 \\
\hline Franca (E) & 287.400 & 97,80 & 168.413 \\
\hline Itapetininga (E) & 125.192 & 89,86 & 73.920 \\
\hline Itapeva (E e L) & 82.833 & 75,73 & 49.692 \\
\hline Jales (E e L) & 46.178 & 91,17 & 31.955 \\
\hline Jaú (L) & 111.783 & 94,19 & 72.246 \\
\hline Limeira (E) & 248.632 & 85,64 & 154.867 \\
\hline Lins (E e L) & 65.954 & 97,29 & 44.833 \\
\hline Marília (L) & 197.153 & 96,18 & 125.327 \\
\hline Ourinhos (E) & 93.796 & 94,47 & 57.648 \\
\hline Piracicaba (E e L) & 328.312 & 96,25 & 204.287 \\
\hline Registro (E) & 53.505 & 80,90 & 35.593 \\
\hline Ribeirão Preto (L) & 505.012 & 99,53 & 323.564 \\
\hline Rio Claro (E) & 168.087 & 96,91 & 107.432 \\
\hline Santos (E) & 417.777 & 99,58 & 327.179 \\
\hline São João da Boa Vista (L) & 77.213 & 91,32 & 51.186 \\
\hline São Joaquim da Barra (E) & 41.593 & 96,99 & 37.304 \\
\hline São José do Rio Preto (L) & 357.862 & 93,79 & 228.801 \\
\hline São José dos Campos (E) & 538.909 & 95,12 & 321.931 \\
\hline Sorocaba (E) & 494.649 & 95,12 & 302.072 \\
\hline Taubaté (L) & 244.107 & 95,53 & 151.104 \\
\hline Tupã (E) & 63.198 & 94,85 & 43.967 \\
\hline Votuporanga (E e L) & 75.565 & 95,67 & 48.403 \\
\hline ( ) Executivo e & & \\
\hline
\end{tabular}

$\left(^{*}\right)$ Executivo e legislativo

Fonte: IBGE - TSE

Para os municípios de Santa Catarina, os dados sobre composição da população, taxa de urbanização e volume do eleitorado mostraram que: (1) três municípios tinham mais de 100.000 habitantes; (2) a taxa de urbanização é desigual; e (3) apenas uma cidade, Joinville, tem um número de eleitores que Ihe permitiria realizar um segundo turno. 
Tabela 13

Amostra dos municípios de Santa Catarina: população, taxa de urbanização e eleitorado, em 2000

\begin{tabular}{|l|c|c|c|}
\hline \multicolumn{1}{|c|}{ Municípios } & População & $\begin{array}{c}\text { Taxa de } \\
\text { Urbanização }\end{array}$ & Eleitorado \\
\hline Alfredo Wagner (E) & 8.857 & 27,92 & 6.772 \\
\hline Araranguá (E) & 54.706 & 82,35 & 36.172 \\
\hline Concórdia (L) & 51.631 & 73,41 & 44,298 \\
\hline Criciúma (L) & 170.420 & 89,80 & 111.448 \\
\hline Curitibanos (L) & 36.061 & 89,95 & 26.662 \\
\hline Joaçaba (L) & 24.068 & 90,11 & 17.802 \\
\hline Joinville (E e L) & 429.604 & 96,59 & 269.536 \\
\hline Lajes (L) & 157.682 & 97,39 & 100.906 \\
\hline São Bento do Sul (L) & 65.437 & 94,48 & 42.214 \\
\hline São Miguel do Oeste (L) & 32.324 & 79,59 & 23.017 \\
\hline
\end{tabular}

$\left({ }^{*}\right)$ Executivo e legislativo

Fonte: IBGE - TSE

Para os municípios de Alagoas, apenas quatro questionários, respondidos pelo executivo, foram devolvidos, o que nos leva a limitar nossa análise aos municípios do estado de Santa Catarina e São Paulo.

\section{Análise}

As variáveis idade e escolaridade foram consideradas as mais adequadas para caracterizar os prefeitos e presidentes de câmara.

O cargo de presidente de câmara tende a ser ocupado por pessoas mais velhas, como mostra a comparação das faixas etárias dos presidentes (50 a 60 anos) e dos vereadores (40 a 50 anos). Em relação à escolaridade, os prefeitos dos municípios e os presidentes de câmara do estado de São Paulo têm o superior completo (apenas um prefeito tem o superior incompleto), conforme mostra a Tabela 15. Para Santa Catarina, é maior a variação da escolaridade de prefeitos e presidentes de câmara. 
Tabela 14

Distribuição dos prefeitos e presidentes de câmara por faixa etária Santa Catarina e São Paulo

\begin{tabular}{|l|c|c|c|c|}
\hline \multicolumn{1}{|c|}{ Estados } & \multicolumn{2}{c|}{ Santa Catarina } & \multicolumn{2}{c|}{ São Paulo } \\
\hline Idade & Prefeitos & $\begin{array}{c}\text { Presidentes } \\
\text { de Câmara }\end{array}$ & Prefeitos & $\begin{array}{c}\text { Presidentes } \\
\text { de Câmara }\end{array}$ \\
\hline De 30 a 40 anos & 1 & 1 & 1 & 0 \\
\hline De 40 a 50 anos & 0 & 3 & 12 & 5 \\
\hline De 50 a 60 anos & 1 & 4 & 5 & 11 \\
\hline Acima de 60 anos & 2 & 0 & 2 & 3 \\
\hline Total & $\mathbf{4}$ & $\mathbf{8}$ & $\mathbf{2 0}$ & $\mathbf{1 9}$ \\
\hline
\end{tabular}

Fonte: Pesquisa Descentralização, Clivagens Regionais e Elites Políticas

Tabela 15

Distribuição dos prefeitos e presidentes de câmara segundo escolaridade Santa Catarina e São Paulo

\begin{tabular}{|l|c|c|c|c|}
\hline \multicolumn{1}{|c|}{ Estados } & \multicolumn{2}{|c|}{ Santa Catarina } & \multicolumn{2}{c|}{ São Paulo } \\
\hline Escolaridade & Prefeitos & $\begin{array}{c}\text { Presidentes } \\
\text { de Câmara }\end{array}$ & Prefeitos & $\begin{array}{c}\text { Presidentes } \\
\text { de Câmara }\end{array}$ \\
\hline $1^{\circ}$ grau incompleto & - & - & - & - \\
\hline $1^{\circ}$ grau completo & 1 & - & - & 1 \\
\hline $2^{\circ}$ grau incompleto & - & 2 & - & 1 \\
\hline $2^{\circ}$ grau completo & 1 & 2 & - & 3 \\
\hline Superior incompleto & 1 & - & 1 & 2 \\
\hline Superior completo & 1 & 2 & 19 & 12 \\
\hline Total & $\mathbf{4}$ & $\mathbf{6}$ & $\mathbf{2 0}$ & $\mathbf{1 9}$ \\
\hline
\end{tabular}

Fonte: Pesquisa Descentralização, Clivagens Regionais e Elites Políticas

Os dados sobre a opção partidária dos prefeitos e presidentes de câmara no início da carreira política, em comparação com a opção atual, apontam que não há uma migração partidária significativa.

Segundo os dados coletados, é grande o número de prefeitos que passaram por experiência eleitoral anterior, ao concorrer por outros cargos eletivos (vereador, deputado estadual ou deputado federal); os presidentes de câmara, por sua vez, muito raramente passaram por outras experiências eletivas. 
Tabela 16

Distribuição dos prefeitos e presidentes de câmara, segundo o partido de início e o partido atual -Santa Catarina e São Paulo

\begin{tabular}{|c|c|c|c|c|c|c|c|c|}
\hline \multirow{3}{*}{\begin{tabular}{|l|} 
Estados \\
Cargos \\
Partidos
\end{tabular}} & \multicolumn{4}{|c|}{ Santa Catarina } & \multicolumn{4}{|c|}{ São Paulo } \\
\hline & \multicolumn{2}{|c|}{ Prefeitos } & \multicolumn{2}{|c|}{ Pres. de Câmara } & \multicolumn{2}{|c|}{ Prefeitos } & \multicolumn{2}{|c|}{ Pres. de Câmara } \\
\hline & Início & Atual & Início & Atual & Início & Atual & Início & Atual \\
\hline PPB & 1 & 2 & 3 & 4 & 1 & 2 & 1 & 1 \\
\hline PPS & & & & & 1 & 1 & 1 & 1 \\
\hline PSDB & & 1 & & & 2 & 2 & 1 & 1 \\
\hline ARENA & & & & & 2 & & & \\
\hline UDN & & & & & 1 & & & \\
\hline PMDB & 1 & 1 & 2 & 3 & & 3 & 2 & 2 \\
\hline $\mathrm{PL}$ & & & 1 & & & & & \\
\hline PT & & & & & 2 & 2 & 2 & 2 \\
\hline PDS & & & & & 1 & & 2 & 2 \\
\hline PTN & & & & & & 1 & 1 & 1 \\
\hline PDT & & & & & 1 & 3 & 3 & 3 \\
\hline PCB & & & & & 2 & 1 & 1 & 1 \\
\hline MDB & 1 & & & & 3 & & 1 & 1 \\
\hline PFL & 1 & & 1 & 1 & 1 & 2 & 2 & 2 \\
\hline PC DO B & & & & & & 1 & 1 & 1 \\
\hline PSD & & & 1 & & 2 & 1 & 1 & 1 \\
\hline $\begin{array}{l}\text { Não } \\
\text { respondeu }\end{array}$ & & & & & 1 & 1 & & \\
\hline Total & 4 & 4 & 8 & 8 & 20 & 20 & 19 & 19 \\
\hline
\end{tabular}

Fonte: Pesquisa Descentralização, Clivagens Regionais e Elites Políticas

A opção partidária inicial e atual dos prefeitos e presidentes de câmara de Santa Catarina mostra-se concentrada nos grandes partidos. A opção partidária inicial e atual dos prefeitos e presidentes de câmara de São Paulo é mais pulverizada, e percorre uma gama variada de partidos. Alguns presidentes de câmara em São Paulo começaram a carreira sob o sistema partidário anterior a 1979, tendo pertencido a partidos como a Arena ou o MDB.

Segundo a opinião dos prefeitos e presidentes de câmara entrevistados, o relacionamento entre o executivo e o legislativo, geralmente considerado de total submissão do segundo ao primeiro, foi avaliado como bom e regular, portanto, estável, apesar dos inúmeros conflitos tornados públicos nos últimos anos por conta da ação fiscalizadora do legislativo. Segundo a percepção dos atores envolvidos, nem a submissão total, nem o atrito permanente parecem caracterizar esta relação (Tabela 17). 
Tabela 17

Avaliação da relação entre o executivo e o legislativo no município

\begin{tabular}{|l|c|c|c|c|c|}
\hline \multicolumn{1}{r}{$\begin{array}{c}\text { Estados e } \\
\text { Cargos }\end{array}$} & \multicolumn{2}{c|}{ Santa Catarina } & \multicolumn{2}{c|}{ São Paulo } & \multirow{2}{*}{ Total } \\
\cline { 1 - 5 } Avaliação & Prefeitos & $\begin{array}{c}\text { Presidente de } \\
\text { Câmara }\end{array}$ & Prefeitos & $\begin{array}{c}\text { Presidente de } \\
\text { Câmara }\end{array}$ & \\
\hline Ótimo & 1 & 1 & 5 & 1 & 8 \\
\hline Bom & 2 & 4 & 9 & 9 & 24 \\
\hline Regular & 1 & 3 & 4 & 7 & 15 \\
\hline Ruim & & & 1 & 2 & 3 \\
\hline Péssimo & & & & & 1 \\
\hline Não respondeu & & & 1 & & 19 \\
\hline Total & $\mathbf{4}$ & $\mathbf{8}$ & $\mathbf{2 0}$ & 19 & \\
\hline
\end{tabular}

Fonte: Pesquisa Descentralização, Clivagens Regionais e Elites Políticas

Avaliado de forma cuidadosa por prefeitos e presidentes de câmara, o relacionamento com o judiciário - que tem desempenhado um papel fundamental no controle da corrupção, da Lei de Responsabilidade Fiscal e do Estatuto da Cidade (especialmente através da promotoria pública) - foi considerado bom e ótimo.

Tabela 18

Avaliação da relação entre o executivo e o judiciário no município

\begin{tabular}{|l|c|c|c|c|}
\hline \multicolumn{1}{|c|}{$\begin{array}{c}\text { Estados e } \\
\text { Cargos }\end{array}$} & \multicolumn{2}{c|}{ Santa Catarina } & \multicolumn{2}{c|}{ São Paulo } \\
\hline Avaliação & Prefeitos & $\begin{array}{c}\text { Presidente de } \\
\text { Câmara }\end{array}$ & Prefeitos & $\begin{array}{c}\text { Presidente de } \\
\text { Câmara }\end{array}$ \\
\hline Ótimo & 2 & 3 & 5 & 1 \\
\hline Bom & 2 & 3 & 10 & 10 \\
\hline Regular & & 2 & 4 & 6 \\
\hline Ruim & & & & 1 \\
\hline Péssimo & & & 1 & 1 \\
\hline Não respondeu & & & & $\mathbf{1 9}$ \\
\hline Total & $\mathbf{4}$ & $\mathbf{8}$ & $\mathbf{2 0}$ & \\
\hline
\end{tabular}

Fonte: Pesquisa Descentralização, Clivagens Regionais e Elites Políticas

A criação dos conselhos municipais redesenhou as relações favorecidas em espaços já institucionalizados no município e ajudou a incorporar novos atores políticos aptos a participar da formulação e implementação de políticas públicas. Este novo desenho institucional ajudou a articular os atores tradicionais da política local, ligados a práticas políticas consagradas, como a autonomização do executivo 
em relação ao legislativo, a legislação social, quase sempre do executivo, a perda do equilíbrio entre executivo e legislativo, o fortalecimento do judiciário, com os novos atores políticos, em geral, associados aos movimentos populares e sindical e às lideranças surgidas entre usuários de serviços públicos, cujos interesses se fazem representar de modo organizado.

Segundo os entrevistados, o funcionamento dos conselhos municipais foi considerado bom e regular, embora os presidentes de câmara de São Paulo tenham uma percepção mais negativa dos conselhos, do que os de Santa Catarina (Tabela 19).

Tabela 19

Avaliação do funcionamento dos conselhos municipais

\begin{tabular}{|l|c|c|c|c|c|}
\hline \multicolumn{1}{|c|}{$\begin{array}{c}\text { Estados e } \\
\text { Cargos }\end{array}$} & \multicolumn{2}{c|}{ Santa Catarina } & \multicolumn{2}{c|}{ São Paulo } & \multirow{2}{*}{ Total } \\
\cline { 1 - 5 } Avaliação & Prefeitos & $\begin{array}{c}\text { Presidente de } \\
\text { Câmara }\end{array}$ & Prefeitos & $\begin{array}{c}\text { Presidente de } \\
\text { Câmara }\end{array}$ & \\
\hline Ótimo & & & 2 & 5 & 7 \\
\hline Bom & 3 & 6 & 9 & 2 & 20 \\
\hline Regular & 1 & 1 & 9 & 10 & 21 \\
\hline Ruim & & 1 & & 2 & 3 \\
\hline Péssimo & & & & & \\
\hline Total & $\mathbf{4}$ & $\mathbf{8}$ & $\mathbf{2 0}$ & $\mathbf{1 9}$ & \\
\hline
\end{tabular}

Fonte: Pesquisa Descentralização, Clivagens Regionais e elites Políticas

Ao conferir aos conselhos municipais competências antes exercidas pelo executivo e pelo legislativo, a legislação manteve as competências desses órgãos representativos como locus das decisões políticas locais, e o sistema de contrapesos e vigilância recíproca. Aparentemente, esta nova institucionalidade encontra dificuldades para reconfigurar as decisões políticas locais, tornando muitas vezes a participação um mero instrumento legitimador das decisões dos órgãos executivos ${ }^{10}$.

Se isto está de fato acontecendo, o executivo municipal vê aumentar o seu poder de decisão, ao mesmo tempo em que tem que dividir as negociações formais e informais com um legislativo enfraquecido e com conselhos homologadores e não deliberativos de decisões sobre políticas públicas. A competição entre representação e participação revela-se na capacidade de legitimar decisões, comum a estas duas instâncias.

\footnotetext{
10 Não existem pesquisas que demonstrem que a formalização das instâncias de participação alterou o processo de decisão local sobre políticas públicas.
} 
Diante desta nova institucionalidade, haverá mudanças no comportamento e na produção dos membros do legislativo? E quais serão os impactos, na relação entre representantes e representados, com o aparecimento de novos atores políticos no processo decisório local? Avaliar a percepção dos atores políticos tradicionais sobre a tomada de decisão em políticas públicas locais pode sinalizar as possíveis modificações provocadas pelos novos arranjos institucionais locais.

Segundo a visão do executivo e de presidentes de câmara, é o prefeito quem prioritariamente formula as políticas públicas. O segundo formulador de políticas. na visão dos prefeitos, é o conselho municipal; para os presidentes de câmara, é o legislativo. Em seguida, o executivo considera o legislativo e as Secretarias como os terceiros formuladores de políticas públicas. Os presidentes de câmara indicaram o Orçamento Participativo e chamaram a atenção para uma certa competição entre legislativo e Orçamento Participativo, ainda não devidamente analisada.

Os prefeitos de Santa Catarina apontam os conselhos municipais como formuladores de políticas públicas; para os presidentes de câmara daquele estado, esse papel cabe às secretarias. Em São Paulo, prefeitos e presidentes de câmara apontam o executivo como responsáveis pela formulação de políticas públicas.

Tabela 20

Quem formula as políticas públicas, segundo o executivo e presidentes de câmara

\begin{tabular}{|l|c|c|c|c|}
\hline \multicolumn{1}{|c|}{ Estados e Cargos } & \multicolumn{2}{c|}{ Santa Catarina } & \multicolumn{2}{c|}{ São Paulo } \\
\hline Opção & Prefeitos & $\begin{array}{c}\text { Presidente de } \\
\text { Câmara }\end{array}$ & Prefeitos & $\begin{array}{c}\text { Presidente de } \\
\text { Câmara }\end{array}$ \\
\hline Executivo & 3 & 5 & 16 & 15 \\
\hline Legislativo & 3 & 3 & 11 & 12 \\
\hline Conselhos municipais & 4 & 1 & 11 & 8 \\
\hline Secretarias & 3 & 7 & 8 & 7 \\
\hline Associações profissionais & 1 & 2 & 7 & 2 \\
\hline Mobilização popular & 2 & 3 & 6 & 3 \\
\hline Orçamento Participativo & 1 & 4 & 6 & 4 \\
\hline Empresas privadas & 1 & 1 & 2 & 1 \\
\hline
\end{tabular}

Fonte: Pesquisa Descentralização, Clivagens Regionais e Elites Políticas

Estas respostas sugerem a existência de diferentes arranjos institucionais nos municípios de diferentes estados e trazem para a cena política a figura dos secretários municipais. Essa percepção é permeada pelo critério tecnocrático de que a análise custo/benefício é considerada a escolha mais adequada. Ressalta-se, ainda, a necessidade crescente de os secretários se profissionalizarem e se adequarem às novas exigências da gestão local. Neste processo, adquirem importância na arena decisória, uma vez que dominam as informações necessárias à tomada de decisão e ao desempenho nos meandros da estrutura burocrática. 
Se os conselhos municipais são, de fato, os formuladores da política municipal, como aponta o executivo de Santa Catarina, as decisões tomadas e as formulações propostas estariam sob debate constante e sob o escrutínio público.

Se, por outro lado, esse papel é desempenhado pelo executivo, segundo a percepção de prefeitos e presidentes de câmara de São Paulo, haveria uma racionalidade político sistêmica, na qual o ator principal do jogo político é o prefeito. Apesar de a Constituição de 1988 ter determinado maior autonomia aos legislativos e a possibilidade de serem introduzidas emendas ao orçamento, os legislativos locais têm se deparado com imensas dificuldades ${ }^{11}$. A constituição da maioria absoluta, por exemplo, exige uma mobilização de apoios difíceis a cada votação, quer pelo executivo, quer pelo legislativo, dada a fragmentação dos interesses partidários e políticos que caracterizam os legislativos locais. Outro elemento que pode interferir neste processo é o poder de veto do chefe do executivo, que the permite barrar, total ou parcialmente, um projeto aprovado pelo legislativo.

A Tabela 21 mostra quais foram os atores apontados como aqueles que realmente implementam as políticas públicas. E estas respostas se diferenciam daquelas dadas sobre quem são os formuladores de políticas públicas.

Tabela 21

Quem implementa as políticas públicas, segundo o executivo e presidentes de câmara

\begin{tabular}{|l|c|c|c|c|}
\hline \multicolumn{1}{|c|}{ Estados e Cargos } & \multicolumn{2}{c|}{ Santa Catarina } & \multicolumn{2}{c|}{ São Paulo } \\
\hline Opção & Prefeitos & $\begin{array}{c}\text { Presidente de } \\
\text { Câmara }\end{array}$ & Prefeitos & $\begin{array}{c}\text { Presidente de } \\
\text { Câmara }\end{array}$ \\
\hline Executivo & 3 & 6 & 17 & 15 \\
\hline Legislativo & 1 & 3 & 9 & 15 \\
\hline Conselhos municipais & 2 & 3 & 11 & 6 \\
\hline Secretarias & 4 & 2 & 11 & 8 \\
\hline Associações profissionais & & & & 2 \\
\hline Base partidária & & 1 & 1 & 3 \\
\hline Mobilização popular & 1 & 4 & 5 & 3 \\
\hline Orçamento Participativo & 1 & 3 & 2 & 3 \\
\hline Sociedade civil & 2 & & 4 & \\
\hline
\end{tabular}

Fonte: Pesquisa Descentralização, Clivagens Regionais e Elites Políticas

\footnotetext{
${ }^{11}$ Dada a escassez de estudos sobre a atuação do legislativo municipal, torna-se difícil extrapolar para o município as análises efetuadas por Figueiredo e Limongi (1995) a respeito do predomínio do executivo no processo de formulação, combinado a um padrão cooperativo entre estes dois poderes.
} 
Segundo os prefeitos, as políticas são implementadas pelo próprio executivo, pelas secretarias e pelos conselhos municipais. Para os presidentes de câmara, cabe ao executivo, ao legislativo, às secretarias e aos conselhos municipais implementar as políticas formuladas.

Estes dados mostram a importância fundamental que o executivo tem neste processo, apontado pela maioria dos entrevistados como o maior responsável pela implementação de políticas públicas; o legislativo é visto como grande implementador pelo próprio legislativo e muito pelo executivo.

Setores da sociedade civil tiveram maior participação através dos conselhos municipais, embora ainda não Ihes seja facultado tomar parte efetiva nas decisões nem na implementação de políticas, considerada muitas vezes apenas um valor instrumental para o aperfeiçoamento dos projetos administrativos na sua fase de formulação.

A análise das respostas dadas a respeito dos agentes que têm poder meramente indicativo nas decisões de políticas locais mostra que os atores apontados são aqueles mesmos responsáveis pela formulação e implementação, não tendo sido aberto espaço para a entrada de novos participantes, nem tendo sido permitida a ampliação da cidadania.

Tabela 22

Agentes com poder meramente indicativo nas decisões de políticas públicas, segundo o executivo e presidentes de câmara

\begin{tabular}{|l|c|c|c|c|}
\hline \multicolumn{1}{|c|}{ Estados e Cargos } & \multicolumn{2}{c|}{ Santa Catarina } & \multicolumn{2}{c|}{ São Paulo } \\
\hline Opção & Prefeitos & $\begin{array}{c}\text { Presidente de } \\
\text { Câmara }\end{array}$ & Prefeitos & $\begin{array}{c}\text { Presidente de } \\
\text { Câmara }\end{array}$ \\
\hline Executivo & & & 1 & 3 \\
\hline Legislativo & 2 & 2 & 6 & 12 \\
\hline Conselhos municipais & 3 & 1 & 7 & 9 \\
\hline Secretarias & & 4 & 7 & 7 \\
\hline Bases partidárias & 3 & 4 & 5 & 7 \\
\hline Associações profissionais & & & & 3 \\
\hline Mobilização popular & 2 & 1 & 3 & 1 \\
\hline Orçamento Participativo & 1 & 1 & 1 & 4 \\
\hline Empresas privadas & 1 & & & 6 \\
\hline Sociedade civil & 1 & 3 & & \\
\hline
\end{tabular}

Fonte: Pesquisa Descentralização, Clivagens Regionais e Elites Políticas

Segundo os prefeitos de Santa Catarina e de São Paulo, os conselhos municipais, o legislativo, a base partidária e as secretarias exercem poder meramente indicativo nas decisões de políticas públicas. Segundo os presidentes de câmara, o poder indicativo nas decisões é do legislativo, dos conselhos municipais, das bases partidárias e das secretarias. 
É interessante observar que, nas respostas a esta questão, o executivo aparece muito superficialmente, enquanto o legislativo e os conselhos municipais aparecem de forma muito clara, corroborando as teses sobre a fraca capacidade destas instituições de definirem o processo decisório e fortalecerem o executivo.

As clivagens regionais estaduais mostradas nestes dados servem para explicar as diferentes percepções dos atores políticos sobre os arranjos decisórios locais e impõem limites às mudanças institucionais. As enormes diferenças socioeconômicas e financeiras entre estados e entre municípios de um estado interferem na escolha pública, na negociação, na formulação e na implementação de políticas locais.

Há, em São Paulo (um estado mais urbanizado e com municípios maiores) e em Santa Catarina (um estado menos urbanizado e com municípios menores), percepções diferenciadas sobre o processo decisório e entre o executivo e o legislativo, por conta da estrutura partidária e da origem de suas elites. Apesar de todas as dificuldades para estabelecer relações entre a percepção de atores políticos e os arranjos e negociações efetivamente realizadas pelo governo local, a análise da percepção oferece-nos pistas importantes sobre a relação entre executivo e legislativo, referendando o consenso sobre um executivo local forte que se sobrepõe a um legislativo fraco.

\section{Conclusões}

O governo municipal vive hoje, em decorrência das novas regras sobre as relações intergovernamentais e das novas funções que deve exercer, um período de reconfiguração da arena decisória e dos processos de tomada de decisão, convivendo com duas lógicas distintas e contraditórias: (1) o tradicionalismo e as ações clientelistas que sempre caracterizaram o poder local e (2) os procedimentos universais que caracterizariam ações mais inovadoras das lideranças locais.

Aparentemente, os poucos estudos disponíveis sobre o legislativo local apontam para a manutenção de suas características seculares, relacionadas à baixa capacidade de legislar e a uma atuação fraca diante de um executivo forte.

Vários fatores internos e externos serviriam para explicar esta atuação, que não sofreu alterações apesar de mudanças nos arranjos institucionais locais, no aumento da circulação da informação e da criação de mecanismos de interlocução com a sociedade civil. 
A confirmação deste papel do legislativo local depende de uma agenda de pesquisa que cubra as várias possibilidades de análise que o tema oferece, o que poderia contribuir para um melhor entendimento da democracia no Brasil, já que é nos municípios que a dinâmica da representação e da participação tem alcançado sua maior expressão.

Para além da relação entre executivo e legislativo local, dos procedimentos legislativos e dos constrangimentos que o sistema eleitoral e partidário acarretam sobre o legislativo e seus membros, os dados nacionais sobre a sua composição sugerem que esta instituição cumpre importantes funções, tanto eleitoraispartidárias quanto relativas à socialização das elites.

\section{Referências Bibliográficas}

ABRUCIO, F. L.; COUTO, C. G. A redefinição do papel do Estado no âmbito local. São Paulo em Perspectiva, v. 10, n. 3, p. 3-143, jul./set. 1996.

ALMEIDA, M. H. T.; CARNEIRO, L. P. Liderança local, democracia e políticas públicas no Brasil. Opinião Pública, v. 9, n. 1, p. 21.42, maio 2003.

ANDRADE, R. de C. (org.). Processo de governo no município e no estado. São Paulo: Edusp, 1998.

AVELINO Filho, G. Cliente e política no Brasil, revisitando velhos problemas. Novos Estudos, n. 38, p. 225-240, mar. 1994.

ÁVILA Filho, P. et al. Legislativo municipal e intermediação de interesses: notas de pesquisa. $4^{\circ}$ Encontro da ABCP, 2004. CD-Rom.

AVRITZER, L. Modelos de deliberação democrática: uma análise dos orçamentos participativos no Brasil. In: SOUZA SANTOS, B. de (org.). Democratizar a democracia: os caminhos da democracia participativa. Rio de Janeiro: Civilização, 2002.

BOSCHI, R. Descentralização, clientelismo e capital social na governança urbana: comparando Belo Horizonte e Salvador. Dados, Revista de Ciências Sociais, v. 42, n. 4, p. 569. 808, 1999. 
BRASIL. Constituição da República Federativa do Brasil, 14. ed., Rio de Janeiro: DP \& A Editora, 2003 (Atualizada pelo EC 40).

CORADINI, O. L. Em nome de quem? Recursos sociais no recrutamento de elites políticas. Rio de Janeiro: Relume Dumará, 2001.

COUTO, C. G. Negociação, decisão e governo: padrões interativos na relação executivolegislativo e o caso paulistano. In: ANDRADE, R. de C. (org.). Processo de governo no município e no Estado. São Paulo: Edusp, 1998.

FIGUEIREDO, A.; LIMONGI, F. Executivo e legislativo na nova ordem constitucional. Rio de Janeiro: FGV, 1999.

KERBAUY, M. T. M. A morte dos coronéis: política interiorana e poder local. Araraquara: Laboratório Editorial/Unesp, 2000.

Federalismo, descentralização e democracia. Estudos de Sociologia, v. 6, n. 10, p. 51. $62,1^{\circ}$ semestre 2001.

LEAL, V. N. Coronelismo, enxada e voto: o município e o regime representativo no Brasil. São Paulo: Alfa-Ômega, 1975.

MAINWARING, S. P. Sistemas partidários em novas democracias. O caso do Brasil. Rio de Janeiro: FGV, 2001.

MARENCO DOS SANTOS, A. Nas fronteiras do campo político: raposas e outsiders no Congresso Nacional. Revista Brasileira de Ciências Sociais, n. 33, p. 87-101, 1997.

MELLO, M. A. Municipalismo, nation-building e a modernização do estado no Brasil. Revista Brasileira de Ciências Sociais, n. 23, p. 8-100, out. 1993.

MESSEMBERG, D. A elite parlamentar do pós-constituinte: atores e práticas. São Paulo: Brasiliense, 2002.

NUNES, E. A gramática política no Brasil. Clientelismo e insulamento democrático. Rio de Janeiro: Zahar, 1999.

PACKENHAM, R. A. Como o legislativo ajuda ou não o desenvolvimento: um enfoque e algumas hipóteses. In: MENDES, C. (org.). O legislativo e a tecnocracia. Rio de Janeiro: Imago, 1975. 
PEREIRA, C.; RENNO, L. O que é que o reeleito tem? Dinâmicas político-institucionais locais e nacionais nas eleições de 1998 para a Câmara dos Deputados. Dados, v. 44, n. 2, p. 323. 362, 2001.

PRALON, E. M. ; FERREIRA, G. N. Centralidade da Câmara Municipal de São Paulo no processo decisório. In: ANDRADE, R. de C. (org.). Processo de governo no município e no Estado. São Paulo: Edusp, 1998.

RODRIGUES, L. M. Partidos, ideologia e composição social: um estudo das bancadas na Câmara dos Deputados. São Paulo: Edusp, 2002.

SAMUELS, D. Financiamento de campanha e eleições no Brasil. In: BENEVIDES, M. V. et al. (org.). Reforma política e cidadania. São Paulo: Fundação Perseu Abramo, 2003.

SANTOS, F. (org.). O poder legislativo nos estados: diversidade e convergência. Rio de Janeiro: FGV, 2001.

. Deputados federais e instituições legislativas no Brasil - 1946-99. In: BOSCHI, R.; DINIZ, E.; SANTOS, F. Elites políticas e econômicas no Brasil contemporâneo. São Paulo: Fundação Konrad Adenauer, 2000.

. Microfundamentos do clientelismo político no Brasil 1959-1963. Dados, v. 38, n. 3, p. 459.496, 1995.

SANTOS, W. G. As razões da desordem. Rio de Janeiro: Rocco, 1993.

SCALON, M. C. Mobilidade social no Brasil: padrões e tendências. Rio de Janeiro: Revan, 1999.

SOUZA, R. B. Clientelismo e voto na Califórnia fluminense. $28^{\circ}$ Encontro Anual da Anpocs, Caxambu, 2004. CD Rom.

TATAGIBA, L. Os conselhos gestores e a democratização das políticas públicas no Brasil. In: DAGNINO, E. (org.). Sociedade civil e espaços públicos no Brasil. São Paulo: Paz e Terra, 2002.

Recebido para publicação em dezembro de 2004. Aprovado para publicação em março de 2005. 